\title{
Structure and functioning of oil cavities in the shoot apex of Metrodorea nigra A. St.-Hil. (Rutaceae)
}

\author{
Silvia Rodrigues Machado ${ }^{1}$ - Yve Canaveze ${ }^{1}$. Tatiane Maria Rodrigues ${ }^{1}$
}

Received: 8 April 2016/Accepted: 30 November 2016/Published online: 12 December 2016

(C) Springer-Verlag Wien 2016

\begin{abstract}
This study investigates the histology and subcellular features of secretory cavities during the development of the shoot apex of Metrodorea nigra A. St.-Hil. in order to better understand the functioning of these glands. This Rutaceae species is a very suitable model for studying secretory cavity life span, since the shoot apex exhibits both dormant and growth stages during its annual cycle. Shoot apices were collected during the dormant and growth stages from populations of M. nigra growing under natural conditions. Materials were processed using standard techniques for light and electron microscopy. The secretory cavities originate under the protodermis, and their initiation is restricted to the early developmental stage of shoot organs, which are protected by a hood-shaped structure. Secretory cavities have a multiseriate epithelium surrounding a lumen that expands schizolysigenously. Oil production begins before lumen formation. When the shoot apex resumes development after the dormant stage, the glands remain active in oil secretion in the developing shoot apex and fully expanded leaves. The mature epithelial cells are flattened and exhibit very thin walls, large oil bodies, leucoplasts surrounded by endoplasmic reticulum, and mitochondria with unusual morphology. The tangential walls of the epithelial cells facing the lumen undergo continuous peeling. The vacuole extrusion appears to be the primary mode of release oil into the lumen, in an exocytotic way. The continuity of oil secretion is ensured by the replacement of the
\end{abstract}

Handling Editor: Alexander Schulz

Silvia Rodrigues Machado

smachado@ibb.unesp.br

1 Departamento de Botânica, Instituto de Biociências de Botucatu, University Estadual Paulista UNESP, Botucatu, São Paulo 18618-970, Brazil damaged inner epithelial cells by divisions in the parenchyma layer that surround the oil gland, likely a meristematic sheath.

Keywords Bud dormancy · Essential oil · Metrodorea nigra · Open growth $\cdot$ Secretory cavity $\cdot$ Ultrastructure

\section{Introduction}

Secretory cavities (glands) are a universal feature of the Rutaceae (Judd et al. 2008) and are present in all parts of the shoot system. These glands are the primary site of both synthesis and accumulation of essential oils (Esau 1965). The Rutaceae essential oils are known for their useful properties in human medicine and also for their defensive functions in the plant. Their bioactive properties include antibacterial, antifungal, and insecticidal activities and thus have been the focus of a number of studies (Regnault-Roger 1997; Oliva et al. 2000; Kalemba and Kunika 2003; Burt 2004; Mandalari et al. 2007). In addition, the essential oils of some Rutaceae species are important as additives in various foods and cosmetics (Jin and Du 2002). Despite the economic and ecological relevance of these essential oils, most studies of the oil cavities in the Rutaceae are limited to the Citrus genus and are focused mainly on the early oil glands development (Carr and Carr 1970; Thomson et al. 1976; Bosabalidis and Tsekos 1982a, b; Turner et al. 1998; Knight et al. 2001; Bennici and Tani 2004; Liang et al. 2006; Chen and Wu 2010; Liu et al. 2012; Turner and Lange 2015). Most of these studies focus on the early development of the gland. Different interpretations exist in the literature concerning the modes of cavity formation, with lysigenous, schizogenous, and schyzolysigenous developmental processes having all been described-again, mostly in Citrus species (Evert 2006; Turner and Lange 2015). 
Irrespective of the mode of cavity formation, the gland life span and the duration of the oil secretion process have both been subjects of some discussion. Most studies have reported that epithelial cells are active for only a limited period, primarily during the early development of the gland, and they then become senescent or die, just after the cavity lumen becomes filled with their secretions (Bosabalidis and Tsekos 1982a, b; Bennici and Tani 2004; Liang et al. 2006; Chen and Wu 2010; Liu et al. 2012). However, other studies have demonstrated that the secretory cells of some Citrus fruit species are much longer lived and remain active in oil production throughout development (Knight et al. 2001; Yamasaki and Akimitsu 2007; Voo et al. 2012; Turner and Lange 2015). Despite these broad analyses, we can find no studies that describe the functioning of oil cavities over an extended period, especially in perennial vegetative organs.

Metrodorea A. St.-Hil. is a neotropical genus of the Rutaceae, known for its hood-shaped structure surrounding the shoot apex, which is formed by modified stipules. Consequently, this structure encloses and provides protection for the meristematic and young tissues of the shoot apex during dormancy. It opens when shoot development and the expansion of young leaves occurs (Cruz et al. 2015). The vegetative apex of Metrodorea plants is structurally complex, exhibiting rhythmic growth with a dormant stage (considered here as the time during which the leaf primordia, young leaves, and internodes cease growth) followed by an expansion stage (when the internodes extend and the preformed leaves expand). Moreover, we consider this plant to offer an excellent model for studies both of gland life span and also of the dynamics of oil secretion.

Metrodorea nigra A. St.-Hil. is a small tree growing at high population density in the understory of semi-deciduous forests of Brazil (Pombal and Morellato 2000). The primary ecological importance of this species in the dynamics of this type of forest is due to its function in the maintenance of high pollinator diversity. It is also a key species for forest restoration (Guidugli et al. 2012) as has been pointed out in a number of studies (Moraes Filho et al. 2015). Here, we conducted a detailed histological and cytological analysis of the secretory cavities in the shoot apex of M. nigra in order to understand the functioning of these glands under natural conditions. We take into account the shoot apices during both their dormant and their expansion stages. Such an approach is desirable to investigate structural and functional traces that could explain the maintenance of secretory activity for an extended period of time.

\section{Materials and methods}

\section{Plant material and study site}

Samples of shoot apices covered with stipules (dormant stage) and with still-expanding and fully developed leaves (expansion stage) were collected from wild populations of $M$. nigra grown in a seasonal, semi-deciduous forest in the Botucatu municipality, São Paulo state, Brazil (22 53' 56.17" $\mathrm{S}$ and $48^{\circ} 29^{\prime} 68.18^{\prime \prime} \mathrm{W}$; $966-\mathrm{m}$ altitude). The regional climate is characterized as hot, with summer rain and winter drought, with an average temperature in the hottest month above $22{ }^{\circ} \mathrm{C}$ and with small hydric deficiencies in April, July, and August (Cunha and Martins 2009). The collection of plant material was conducted over three, noncontiguous periods: from 1997 to 2000 , from 2005 to 2006, and from 2010 to 2013.

Next, the materials were conventionally processed for light and transmission electron microscopy. Vouchers were deposited at the Herbarium BOTU from the Departamento de Botânica, Instituto de Biociências de Botucatu (IBB), Univ. Estadual Paulista (UNESP), Botucatu, São Paulo, Brazil, under the registration number 27752 .

\section{Light microscopy}

To properly analyze the histological organization and the origin of secretory cavities, a minimum of ten shoot apices were fixed for each developmental stage (dormant and expansion) using three conventional processing methods: (1) FAA 50 fixation (Johansen 1940), (2) glutaraldehyde fixation (Feder and O'Brien 1968), and (3) glutaraldehyde fixation plus osmium tetroxide post-fixation (Hayat 1989). To keep the secretory cavities intact, we did not slice the samples during fixation.

FAA 50 Samples were fixed for $48 \mathrm{~h}$ at $4{ }^{\circ} \mathrm{C}$ in a mixture of formaldehyde (5\%), acetic acid (5\%), and ethyl alcohol (50\%); dehydrated using an ethyl alcohol-xylol series; and embedded in paraffin wax. Serial sections (cross and longitudinal, $10-\mu \mathrm{m}$ thick) were cut using a rotatory microtome, stained with safranin solution $(1 \% \mathrm{w} / \mathrm{v})$ and fast green $(0.05 \% w / v)$ (Johansen 1940), and mounted under a coverslip with a synthetic resin (Permount, Electron Microscopy Sciences, Hatfield, USA).

Glutaraldehyde Samples were fixed overnight at $4{ }^{\circ} \mathrm{C}$ in $2.5 \%$ glutaraldehyde in $0.025 \mathrm{M}$ phosphate buffer (Feder and O'Brien 1968), dehydrated through a graded ethanol series, and then processed according to conventional methods for (2-hydroxyethyl)-methacrylate historesin embedding (Leica Microsystems, Nussloch/Heidelberg, Germany). Next, 4-6 $\mu \mathrm{m}$ thick sections were cut using a semiautomatic microtome (Leica RM2245), stained with $1 \%$ toluidine blue in $1 \%$ aqueous sodium tetraborate solution (O'Brien et al. 1964), and mounted in synthetic resin (Entellan, Merck KGaA, Darmstadt, Germany).

Glutaraldehyde-osmium tetroxide Samples were fixed in $2.5 \%$ glutaraldehyde $(0.1 \mathrm{M}$ sodium phosphate buffer, 
$\mathrm{pH} 7.3$, overnight at $4{ }^{\circ} \mathrm{C}$ ) and post-fixed with $1 \%$ osmium tetroxide $\left(\mathrm{O}_{\mathrm{s}} \mathrm{O}_{4}\right)$ in the same buffer for $2 \mathrm{~h}$ at room temperature (Hayat 1989). After washing in distilled water, the material was dehydrated in a graded ethanol series and embedded in Araldite resin. Semi-thin sections $(0.5 \mu \mathrm{m})$ were cut with a microtome and stained with $1 \%$ toluidine blue.

For histochemistry, sections of fresh material obtained, with the aid of a Ranvier microtome, were stained in Sudan IV to detect total lipids in Lugol's reagent for alkaloids (Johansen 1940), in Nadi's reagent (naphtol+dimethylparaphenylene-diamine) for essential oils (David and Carde 1964), in $0.02 \%$ aqueous ruthenium red for polysaccharides and pectin (Jensen 1962), in Schiff's reagent (periodic acidSchiff's_-PAS) for neutral polysaccharides (Jensen 1962), and in mercuric bromophenol blue for proteins (Mazia et al. 1953).

Observations and documentation were carried out using a light microscope (Leica DMR) equipped with a digital camera (Leica DFC 500).

\section{Scanning electron microscopy}

Samples were fixed in glutaraldehyde $(2.5 \%$ with $0.1 \mathrm{~m}$ phosphate buffer, $\mathrm{pH} 7.3$ ) and left overnight at $4{ }^{\circ} \mathrm{C}$, dehydrated in a graded ethanol series, critical-point dried, mounted on aluminum stubs, gold coated, and examined under a scanning electron microscope (FEI Quanta 200) at $20 \mathrm{kV}$.

\section{Transmission electron microscopy}

To analyze the subcellular features of oil cavities, ultrathin $(80 \mathrm{~nm})$ sections of aldehyde plus $\mathrm{O}_{\mathrm{s}} \mathrm{O}_{4}$ post-fixed samples, embedded in Araldite resin, were cut with an ultramicrotome, collected on copper grids, and contrast stained with uranyl acetate and lead citrate (Reynolds 1963). Observations were made using a transmission electron microscope (Tecnai Spirit, FEI Company, Germany) at $60 \mathrm{kV}$.

\section{Results}

\section{Growth dynamics of the shoot apex}

The dry season lasts approximately 4-5 months (MarchAugust) and corresponds to the autumn and winter months. During this period, the shoot apex of $M$. nigra exhibits unextended internodes and unexpanded leaf and axillary bud primordia and young leaves. It is covered by a hood-shaped structure (Fig. 1a) formed by connate intrapetiolar stipules. The unextended internode, leaf primordia, and young leaves remain confined within a chamber formed by the hood-shaped structure (Fig. 1b). In early spring (September), the hoodshaped structure opens to expose the shoot with preformed leaves (Fig. 1c). Paired compound leaves with one, two, or three leaflets (Fig. 1d) emerge as a flush and reach their maximum expansion in the early wet period (October 8-12). Leaf senescence and abscission occur during autumn.

Oil cavities remain active in secretion throughout the development of the shoot apex-during both the dormant (Fig. 1e, f) and the expansion stages (Fig. 1g), suggesting the persistent activity of the epithelial cells from the time of their formation.

\section{Distribution of secretory cavities in the shoot apex}

Secretory cavities at different developmental stages were easily identified side by side, in both longitudinal (Fig. 1e), cross (Fig. 1g), and paradermal sections (Fig. 1h) of the shoot apex in the subepidermal layers of the leaf primordia and young leaves. In the modified stipules (Fig. 1f) and in the fully expanded leaves (Fig. 1i, j), only mature cavities were observed. In expanded leaves, secretory cavities occurred in both in palisade (Fig. 1i) and in spongy (Fig. 1j) parenchyma.

\section{Histochemistry}

The histochemical tests detected the presence of lipophilic and hydrophilic compounds in the epithelial cells and lumen of the secretory cavities (Table 1; Fig. 2a-j). Essential oil (violet stained with Nadi's reagent; Fig. 2a, b) and total lipids (red stained with Sudan IV; Fig. 2c, d) were detected from the early stage of gland development and before lumen formation until maturation of cavities. Alkaloids (black stained with Lugol's reagent; Fig. 2e, f) were detected in the lumen of the secretory cavities. Proteins (blue stained with mercuric bromophenol; Fig. 2g, h) were detected in the protoplast of the epithelial cells and lumen of the secretory cavities. Pectin (pink stained with ruthenium red; Fig. 2i, j) was detected in the walls of the epithelial cells which are very thinner than the walls of the neighboring parenchyma cells. Although the quantity of secretion has not been determined, all the substances were more abundant in the lumen of glands in the modified stipules, leaf primordia, and young leaves in the shoot apex in the dormancy stage. The exudate content seems to decrease in the lumen of secretory cavities in the fully expanded leaves.

\section{Secretory cavity development}

Based on light and transmission electron microscopical observations, the development of the secretory cavities could be divided into three stages as described in the following sections. 
Fig. 1 Shoot apex morphology, distribution, and structure of the secretory cavities of Metrodorea nigra. a-d Shoot apex in different stages of development. a

Dormant shoot apex covered by a woody hood-shaped structure (hss). Note the lenticels. b Scanning electron microscope image of a dissected dormant shoot apex showing compressed leaf primordia $(l p)$ within the hood-shaped structure (hss). c Developing shoot apex with appositional young leaves exposed by the opening of the hss. d Two developing stem axes, each with a pair of trifoliolate-expanding leaves. e Longitudinal section through the shoot apex showing apical meristem (am) and secretory cavities (arrows) in the young leaves in the hss. f, $\mathbf{g}$ Cross sections through the shoot apex. $\mathbf{f}$ Mature cavity filled with secretion in the stipule. Note the periderm. g Leaf primordia $(l p)$ and expanding leaves exhibiting cavities (arrows) in different developmental stages. h Paradermal section through the shoot apex showing maturing oil cavities with expanding lumen and glands in the early stage. $\mathbf{i}, \mathbf{j}$ Cross sections through the leaf blade showing mature secretory cavities with a wide lumen and multiseriate epithelium composed of thin-walled cells. i Adaxial surface. $\mathbf{j}$ Abaxial surface
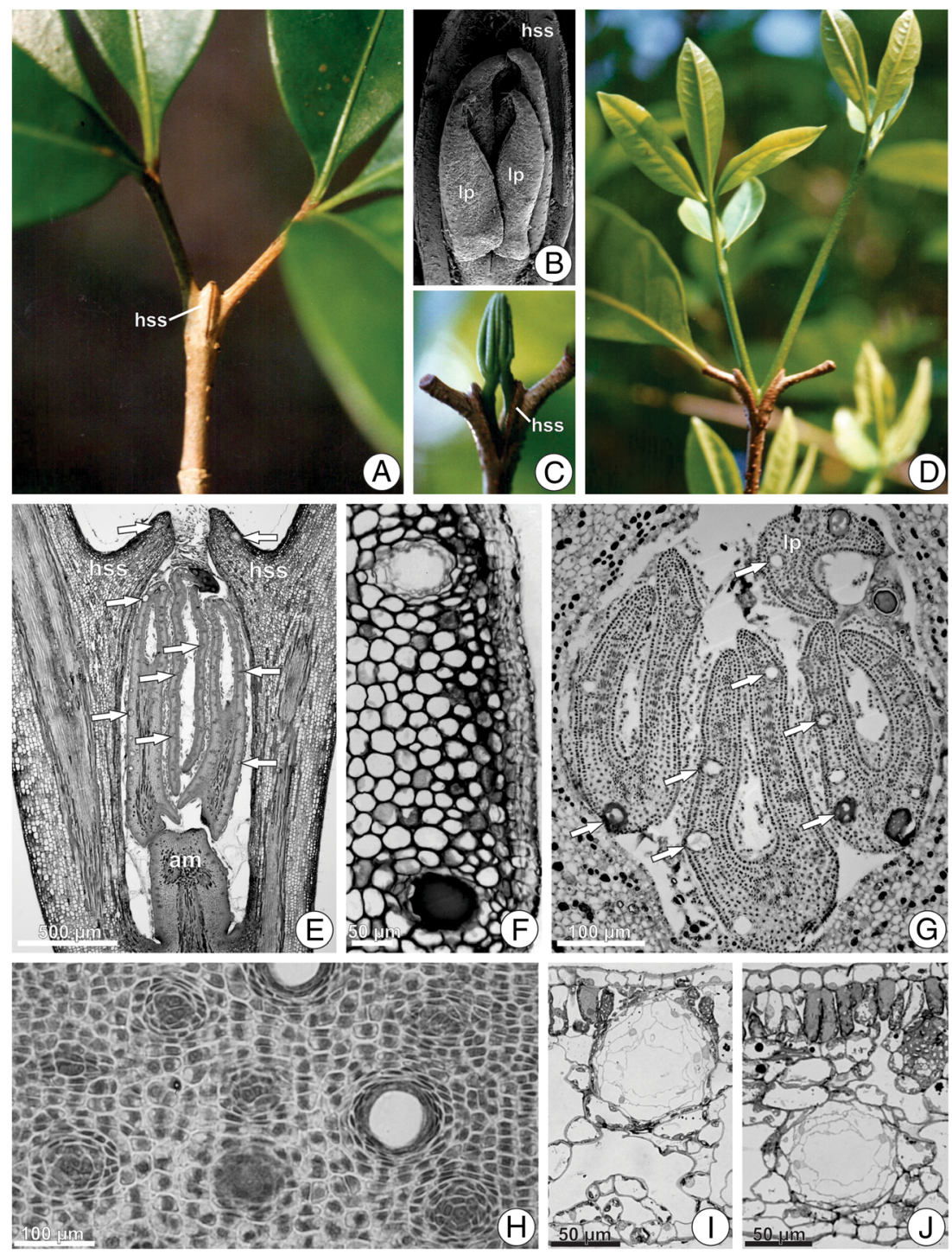

\section{Early secretory cavity development}

The initial cell (Fig. 3a) of the secretory cavity was easily distinguished of the neighboring subepidermal cells by presenting conical or star shape, thin angular cell walls, voluminous nuclei with dense heterochromatin, and dense cytoplasm. These cells exhibited abundance of globular mitochondria and large plastids containing thylakoid membranes, starch grains, and conspicuous lipid drops. Next to the extremities of these initial cells, the middle lamella was swollen and more electron dense.

The initial cell exhibited a sequence of asymmetrical divisions in different planes and originates immediate derivative
Table 1 Histochemistry of secretory cavities in the shoot apex of Metrodorea nigra (Rutaceae)

\begin{tabular}{llcc}
\hline Staining procedure & Target compounds & Epithelial cells & Lumen \\
\hline Sudan IV & Total lipids & + & + \\
Nadi's reagent & Essential oils & + & + \\
Lugol's reagent & Alkaloids & - & + \\
Ruthenium red & Pectin & + & + \\
Schiff (PAS) & Neutral polysaccharides & - & + \\
Mercuric bromophenol blue & Proteins & + & + \\
\hline
\end{tabular}

- no reaction, + positive reaction 

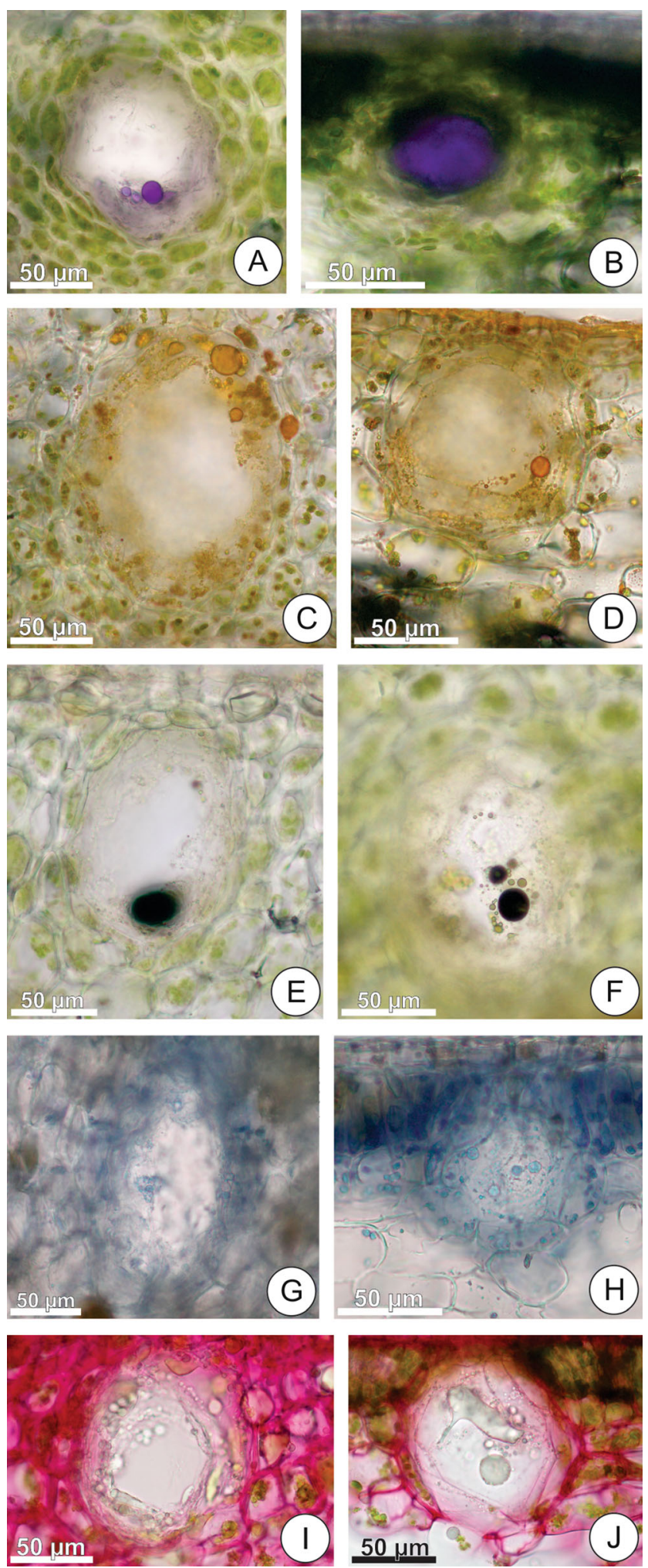

cells of different sizes and shapes (Fig. 3b, c). The derivative cells exhibited a compact arrangement, very thin walls, and thick middle lamellae in the corner, voluminous nucleus with evident nucleolus and dense heterochromatin (Fig. 3d). The vacuoles were small, and the cytoplasm was dense, exhibiting
Fig. 2 Histochemical characterization of secretory products in cross sections through stipules $(\mathbf{a}, \mathbf{c}, \mathbf{e}, \mathbf{g}, \mathbf{i})$ and young leaves $(\mathbf{b}, \mathbf{d}, \mathbf{f}, \mathbf{h}, \mathbf{j})$ of Metrodorea nigra. a, b Detection of terpenoids with Nadi's reagent. a Positive reaction for essential oil in the epithelial cells. b Presence of essential oil in the lumen of the secretory cavity. c, d Lipid detection with Sudan Red. Positive reaction (lipid droplets) on the glandular epithelium. e, f Detection of alkaloids with Lugol's reagent. Positive reaction in the lumen of the cavity. $\mathbf{g}, \mathbf{h}$ Detection of proteins with mercuric bromophenol blue. Positive reaction was observed on the epithelial cells and lumen of secretory cavities. (i, j) Secretory cavities after reaction with ruthenium red, highlighting the very thin walls of epithelial cells. Stronger reaction was observed in the most peripheral cells of the secretory cavities

polysomes, globular mitochondria, multivesicular bodies (Fig. 3e), and scattered oil drops (Fig. 3f g); the plastids contained residual thylakoids and lipidic inclusions (Fig. 3b, c) or were filled with lipids only (Fig. 3e). Plasmodesmata interconnected the derivative cells (Fig. 3e) and also these with the adjacent parenchyma cells (Fig. 3f, g). At this time, clusters of 12 to 16 cells compactly and radially arranged characterized by their dense cytoplasmic contents and large nuclei (Fig. 3h) were identified in the subepidermal region. As differentiation of the secretory cavity progressed, the derivative cells became radially arranged (Fig. 3i). The most peripheral cells in the cluster became flattened tangentially while the central cells were more voluminous and acquired irregular contour and tapered ends (Fig. 3j). During the development of the cluster, the central cells exhibited numerous mediumsized vacuoles which could be filled with lipids (Fig. 3j). Such vacuoles coalesced and originated larger ones. On the light microscope, cluster exhibited a clear central zone due to the development of the vacuome in the central cells (Fig. 3k). By TEM, the central cells exhibited reduced cytoplasm, a large central vacuole, and very thin walls while the peripheral cells have denser cytoplasm and few vacuoles (Fig. 31).

\section{Differentiating secretory cavities}

As the cluster differentiation progressed, an intercellular space with irregular outline was observed in the central region of the cluster (Fig. 4a). This space was surrounded by five to seven voluminous globose cells (Fig. 4a, b). A layer of tabular juxtaposed cells with thicker and dense walls surrounded externally the epithelial cells (Fig. 4a, b). The epithelial cells were featured by the thin walls with loose appearance and the dense cytoplasm rich in polysomes, elongated cisternae of the smooth endoplasmic reticulum (ER) occasionally arranged concentrically, globular mitochondria, scattered lipid drops, and small vacuoles (Fig. 4c).

In a posterior stage, the epithelial cells became more flattened (Fig. 4d, e). The lumen expansion progressed by the dissolution of the radial cell walls (Fig. 4d) and formation of a number of bulbous pockets between the cell walls (Fig. 4e). This process of wall dissolution was continuous during all the 

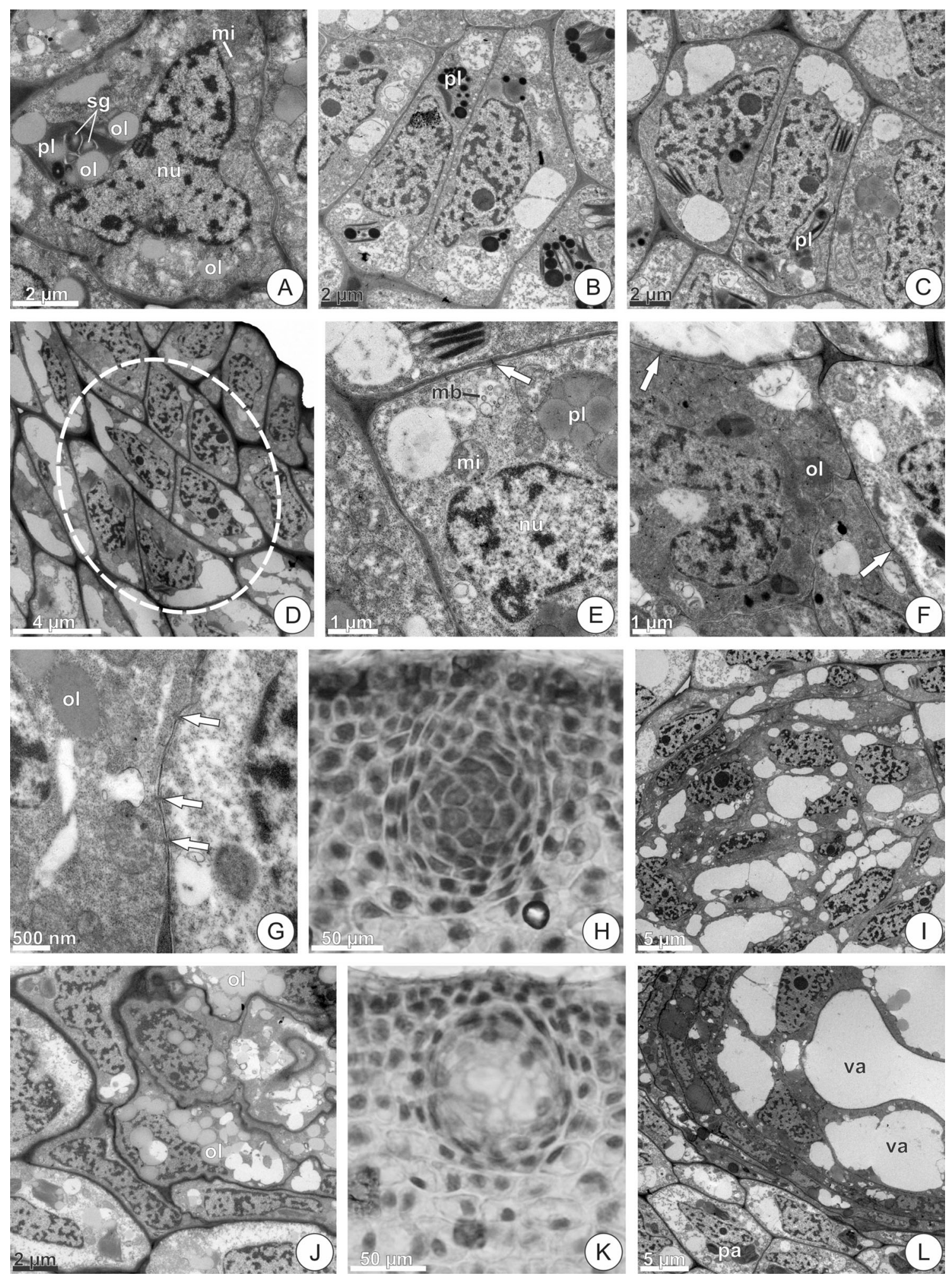

process of gland differentiation. The tangential walls facing the lumen underwent continuous peeling, and fibrillar material could be seen adhering to the wall surface or spreading in the lumen (Fig. 4e). In addition, some epithelial cells facing the lumen showed a large central vacuole and exhibited a tangential protuberance toward the lumen (Fig. 4f). The cell walls facing the lumen became very thin and discontinuous, culminating with the extrusion of their protoplast contents into the lumen (Fig. 4g). As the differentiation progresses, some inner epithelial cells were broken and separated from the 
4 Fig. 3 Early development of secretory cavities in Metrodorea nigra. TEM images $(\mathbf{a}-\mathbf{g}, \mathbf{i}, \mathbf{j}, \mathbf{l})$ and light micrographs $(\mathbf{h}, \mathbf{k})$. a Initial gland cell, recognizable by the star shape with sharpened ends and very thin walls. Note voluminous nucleus $(n u)$, dense and abundant cytoplasm, plastids $(p l)$ with oil and starch grains $(s g)$, and oil $(o l)$ drops scattered in the cytoplasm. $\mathbf{b}-\mathbf{g}$ Immediate derivative cells. $\mathbf{b}, \mathbf{c}$ Newly formed derivative cells with plastids showing residual thylakoids and oil inclusions. d Subprotodermal group consisting of small, recently divided cells with voluminous nucleus and relatively small vacuoles. Observe the swollen and electron-dense middle lamellae in the corners of the cells. e, f Derivative cells showing very thin walls (arrows), nucleus $(\mathrm{nu})$, globular mitochondria $(\mathrm{mi})$, multivesicular body $(\mathrm{mb})$, lipid inclusion $(o l)$, and plastid $(p l)$ filled with lipids drops. g Plasmodesmata (arrows) connecting derivative and adjacent parenchyma cells. Observe derivative cell with denser cytoplasm and oil $(o l)$ inclusion. $\mathbf{h}$ Cluster of derivative cells in the subepidermal region of the leaf primordium, at low magnification. The most peripheral cells exhibit a radial organization. $\mathbf{i}$ Cluster showing peripheral cells flattened tangentially and isodiametric, voluminous inner cells. j Future epithelial cells showing irregular contour and tapered ends that intrude between neighboring cells. Note electrondense, swollen middle lamellae and small vacuole containing oils $(o l)$. $\mathbf{k}$ A general view of a cluster showing a clear central zone due to the development of the vacuome in the central cells. I Larger central cells with reduced cytoplasm, a developed central vacuole $(v a)$, and very thin walls, while the peripheral cells have denser cytoplasm and small vacuoles

epithelium (Fig. 4h). In fact, detached cells, cell debris, and large oil bodies were frequently observed on the inner epithelial cell facing the lumen (Fig. 4h, i).

Differentiating secretory cavities exhibited multiseriate epithelium constituted by four to six layers of cells with dense cytoplasm, evident nucleus, and vacuoles with different sizes (Fig. 5a). The vacuoles enlarge in centripetal direction (Fig. 5b). It is noticeable that the walls of epithelial cells surrounding the lumen are very thin in comparison to the neighboring parenchyma cells (Fig. 5a, b). The outermost epithelial cells were tangentially flattened; their tapered ends become narrower and overlap other epithelial cells (Fig. 5b).

A layer of tabular cells with compact arrangement, thick walls, prominent nucleus, and developed vacuome involved externally the differentiating secretory cavities (Fig. 5b, c). These cells can divide, and the resulting cells differentiate toward the gland, become flattened, acquire denser cytoplasm and prominent nucleus (Fig. 5c), and can divide in the anticlinal plane (Fig. 5d). The new cells have tapered ends that penetrated between the radial walls of the epithelial cells (Fig. 5e), in a way that resembles apical intrusive growth, and became part of the secretory epithelium. The tapered ends of these cells exhibited polysomes, multivesicular bodies containing a number of tubule-vesicular membranes, and paramural bodies (Fig. 5f).

\section{Mature secretory cavities}

In mature cavities with an expanded lumen, the inner epithelial cells exhibited very thin walls and prominent nucleus and developed vacuoles (Figs. 1i, j and 6a) and dense cytoplasm rich in free ribosomes, polysomes, abundant mitochondria rounded to oval in shape, and lipid materials (Fig. 6b). The peeling process of the tangential cell walls is continued even in the mature gland, and residual materials can be observed on the surface of the epithelial cells facing the lumen (Fig. 6b, c). Most mitochondria exhibited large, convolute, and tubular cristae and small electron-dense granules in the matrix (Fig. 6c, d). Some images suggested mitochondrial fission (Fig. 6d). Images suggested that the cristae were connected to one another and to the periphery of the inner membrane, by narrow, dense, tubular junctions, resulting in the formation of symmetrical shapes (Fig. 6c-e). Some mitochondria exhibited oil inclusions (Fig. 6e).

\section{Subcellular changes during the secretory cavity maturation}

Marked changes occurred in the vacuoles, plastids, and sites of oil accumulation during the maturation of epithelial cells. The plastids changes included signs of starch-grain degradation (Fig. 7a, b), accumulation of oil bodies, and decreased in thylakoid membranes (Fig. 7a-c). The plastids became typically leucoplasts (Fig. 7d), and some of them were surrounded by smooth endoplasmic reticulum (Fig. $4 \mathrm{c}-\mathrm{g}$ ). The vacuoles were few and developed in the outermost layers of the secretory epithelium and increased in size, by vacuole coalescence, toward the innermost epithelial cells (Fig. 7e). In the epithelial cell facing the lumen, the larger vacuoles were translucent (probably due to extraction of oil during tissue processing) or contained oil inclusions (Figs. $6 \mathrm{~b}$ and $7 \mathrm{e}$ ). Images suggested that vacuolar membrane merged with the plasma membrane, and, as consequence, their content extruded into the lumen of the secretory cavity (Fig. 4g), in an exocytotic way. The oil drops increased in number and size toward the lumen of the cavity (Fig. 7e-g). Large oil bodies resulting from the fusion of oil drops occurred in the epithelial cells (Fig. 7g).

It is notable that, even before lumen formation, oil droplets were present in the protoplast of gland initial (Fig. 3a) and immediate derivative cells (Fig. 3c, e-g).

\section{Discussion}

Our results clearly show that secretory cavities in $M$. nigra initiate oil production early and remain active in secretion throughout shoot development as well as in the modified intrapetiolar stipules that protect the dormant bud for several months. This finding is consistent with those of previous studies in Citrus, suggesting the prolonged metabolic activity of the epithelial cells of oil cavities throughout fruit development (Knight et al. 2001; Yamasaki and Akimitsu 2007; Voo et al. 2012; Turner and Lange 2015). This result is of particular 

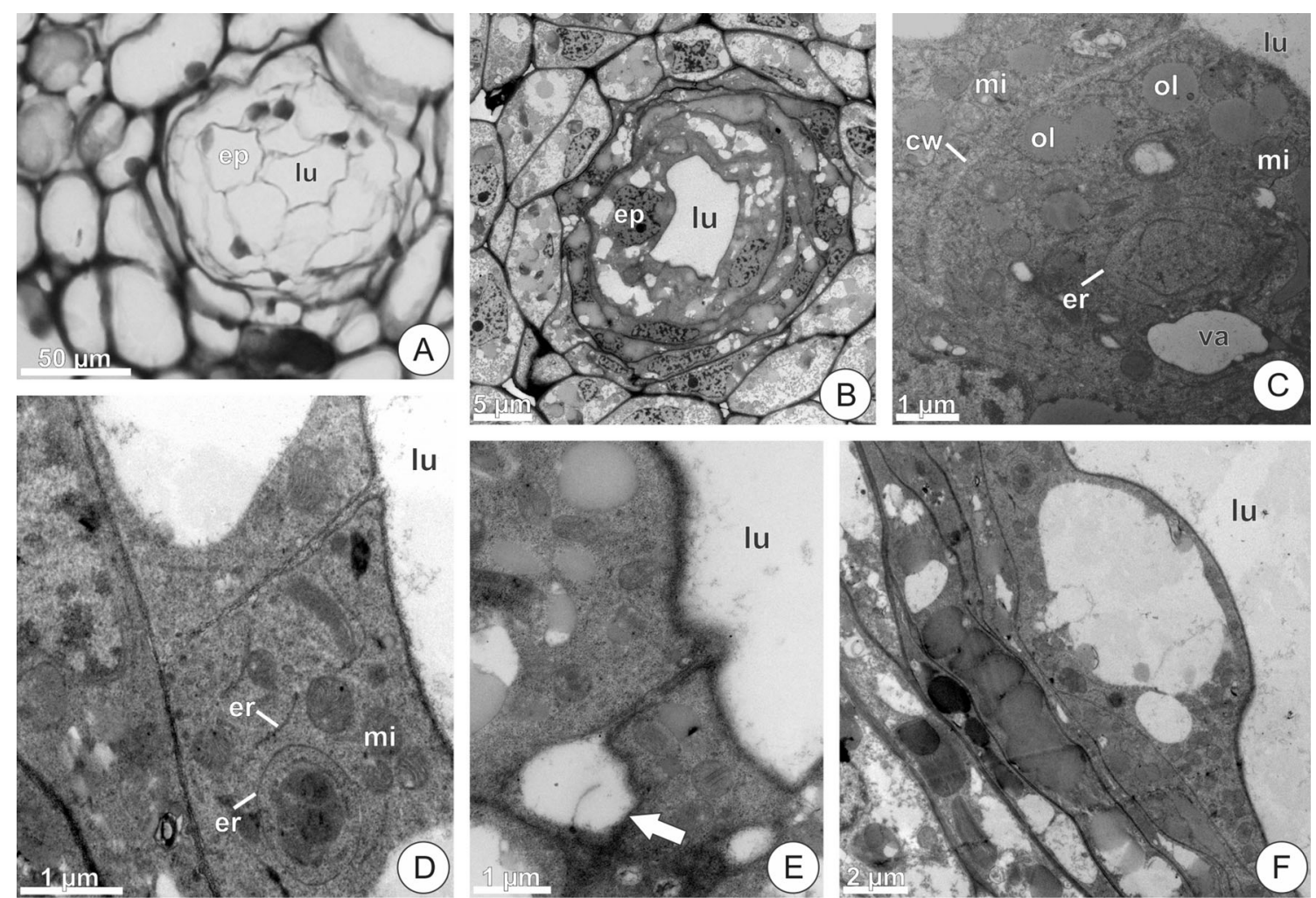
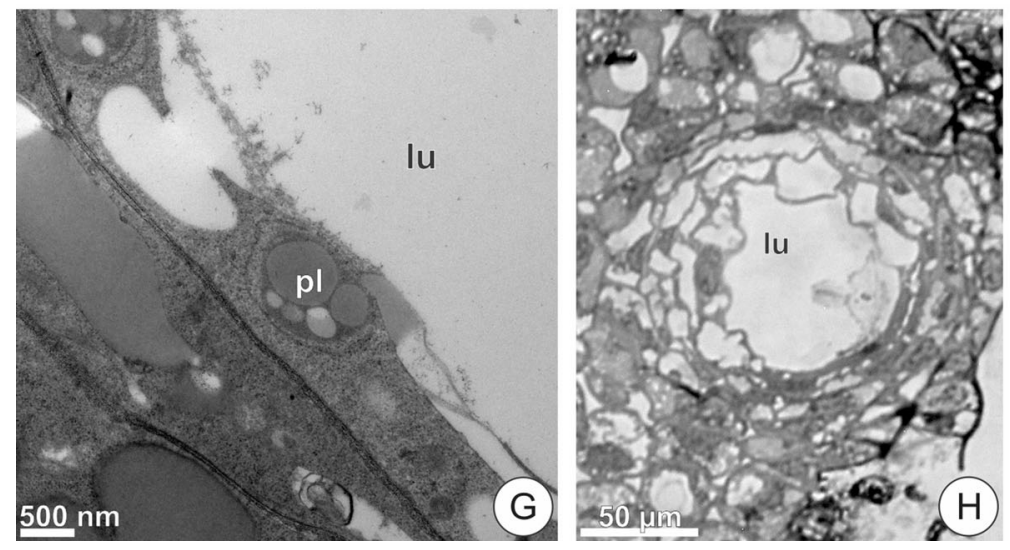

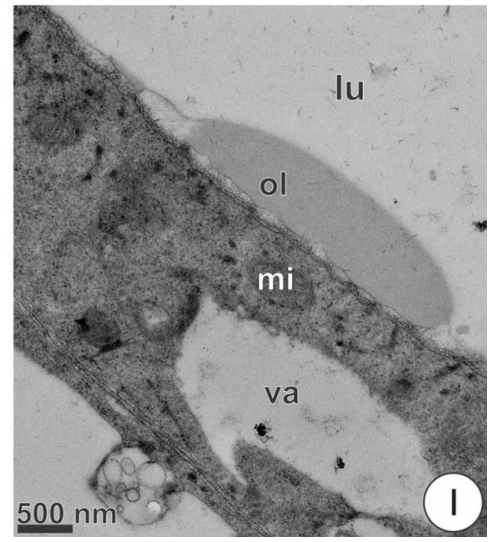

Fig. 4 Differentiating secretory cavities of Metrodorea nigra. Light micrographs (a, h) and TEM images $((\mathbf{b}-\mathbf{g}, \mathbf{i})$. a Medial section of a differentiating gland with a newly formed extracellular storage cavity (lu), likely formed through the separation of cells in the center of the cluster. b General view of a secretory cavity soon after lumen (lu) initialization, that is irregularly contoured and surrounded with globose epithelial cells (ep). Note a layer of tabular, less dense, and thick-walled cells surrounding the gland externally. $\mathbf{c}$ Epithelial cell facing the initiating lumen $(l u)$, exhibiting intact cell wall $(c w)$, polysomes, elongated ER cisternae occasionally arranged concentrically (er), globular mitochondria $(m i)$, scattered oil $(o l)$ drops, and small vacuoles $(v a)$. d Flattened epithelial cells showing signs of dissolution of the middle lamellae through the radial walls. The dense cytoplasm contains polysomes,

importance; we consider that M. nigra is a species not related to the Citrus group.

In the shoot system of $M$. nigra, the secretory cavities originate from meristematic cell groups located in the ground meristem. Their initiation is restricted to the early globular mitochondria (mi), and plastid surrounded with ER elements. Lumen $(l u)$ with fibril-dispersed materials. e Innermost epithelial cells showing bulbous pockets, resulting from the dissolution of the middle lamellae (arrow) along the radial cell walls. Observe the peeling of the cell walls facing the lumen $(l u)$. f Epithelial cell with a tangential protuberance toward the lumen $(l u)$. $\mathbf{g}$ Inner epithelial cell exhibiting thin and discontinuous tangential cell walls and plastid $(p l)$ filled with oils. Note signs of extrusion of the protoplast contents toward the lumen $(l u) . \mathbf{~}$ Immature gland at low magnification showing inner epithelial cells featured by the irregular outline. Note detached epithelial cell in the lumen $(l u)$. i Cell debris and oil $(o l)$ body on the surface of the innermost epithelial cell facing the lumen $(l u)$. mi mitochondria, va vacuole

developmental stage of shoot organs that is protected by a pair of modified stipules forming a hood-shaped structure. Similar findings have been described in fruits of some Citrus species, where oil glands have been observed as early as the ovary stage and enlarge until fruit maturity (Knight et al. 2001). 
Fig. 5 TEM images of differentiating secretory cavities in Metrodorea nigra. a Secretory cavity at low magnification showing multiseriate epithelium $(e p)$ and lumen $(l u)$ with irregular contour. Note larger vacuoles in the innermost layers of the secretory epithelium. b Outermost epithelial cells tangentially flattened, with tapered ends overlapping other epithelial cells. Observe a sheath layer of tabular parenchyma cells $(p a)$ bordering the glandular epithelium. Note oil accumulations in the vacuoles $(v a)$ and lumen $(l u)$. $\mathbf{c}$ Part of a secretory cavity at low magnification, showing flattened cells with prominent nucleus $(n u)$ and dense cytoplasm originated by divisions of the outer parenchyma $(p a)$ cells. Note increase in the oil (oil) inclusions and protoplast extrusion toward the lumen $(l u)$. (D) Higher magnification of the (c) showing newly formed, thin anticlinal walls (arrowhead). e Tapered ends of the newly formed cell overlap between the radial walls of the epithelial cells. f Higher magnification image of a tapered end, showing polysomes,

multivesicular bodies $(\mathrm{mb})$, and paramural bodies
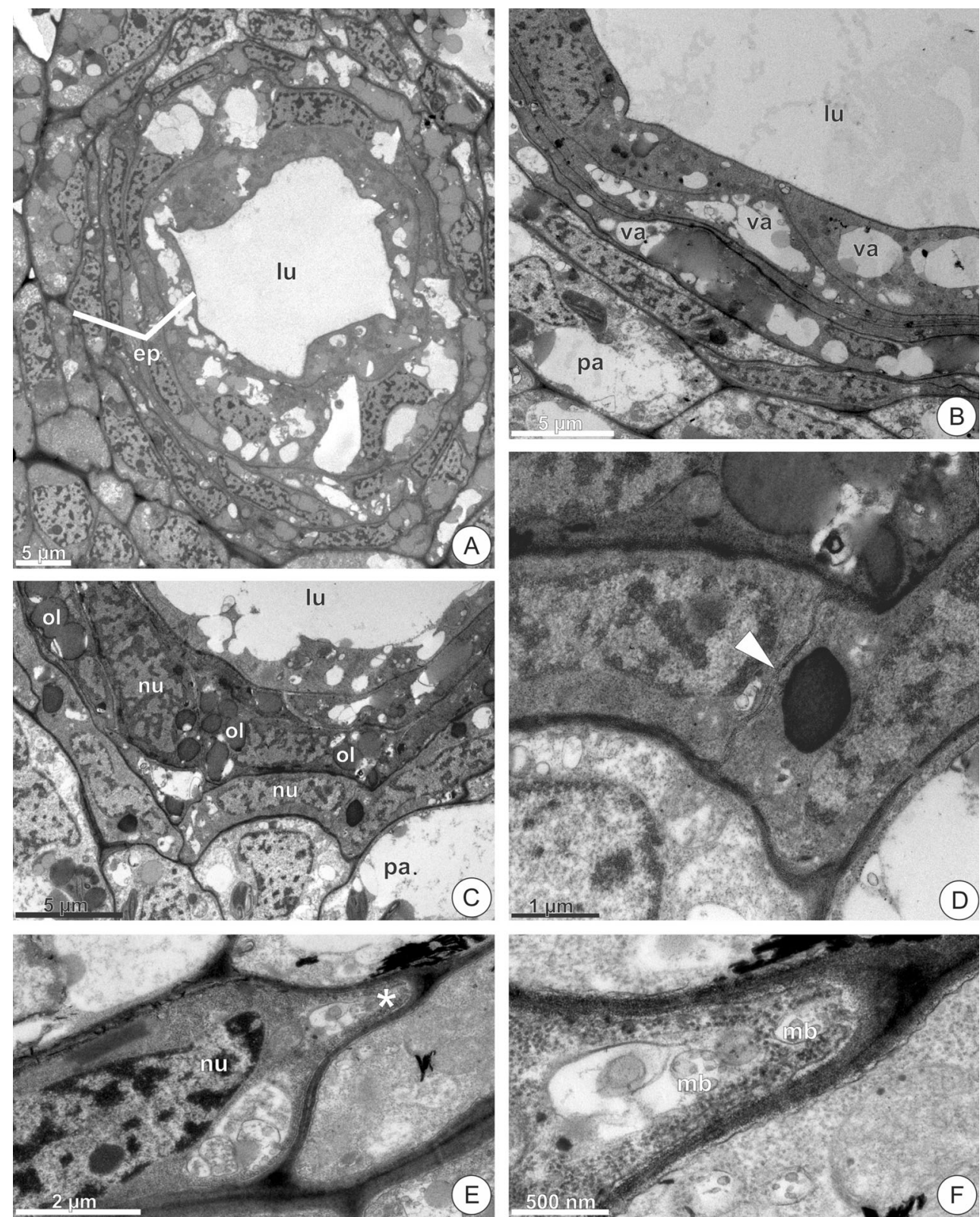

Our light and electron microscope observations, mainly the presence of swollen middle lamellae, provide evidences that suggest the schizogenous origin of the lumen. However, after its arising, the lumen expansion progressed by wall dissolution followed by evident structural disorganization of the protoplasts of some inner epithelial cells culminating in their extrusion into the lumen. In fact, the accumulated secretions in the lumens of mature cavities react positively to staining for essential oils, polysaccharides, and proteins. These events characterize the schizolysigenous process. This pattern is likely to be the most common type of lumen development, as described for Citrus oil cavities (Haberlandt 1914; Thomson et al. 1976; Bosabalidis and Tsekos 1982a, b; Turner et al. 1998; Knight et al. 2001; Bennici and Tani 2004; Liang et al. 2006; Chen and Wu 2010; Liu et al. 2012). The presence of polysaccharides and proteins, in newly formed lumens observed under both light and electron microscopy, may have originated by dissolution of cell wall and intracellular components during early schizolysigenesis (Rodrigues et al. 2011a, 2011b). The secretion of mucilage as reported by Thomson et al. (1976) in Citrus is improbably in this study, since the epithelial cells of $M$. nigra did not show subcellular apparatus consistent to synthesis of these substances.

Considering the controversies in the literature especially on the mechanism of development of oil glands in Citrus (Heinrich 1966, 1969; Thomson et al. 1976; Turner et al. 1998; Bennici and Tani 2004; Liang et al. 2006, 2009), in this study, we made use of a range of methods and techniques for 

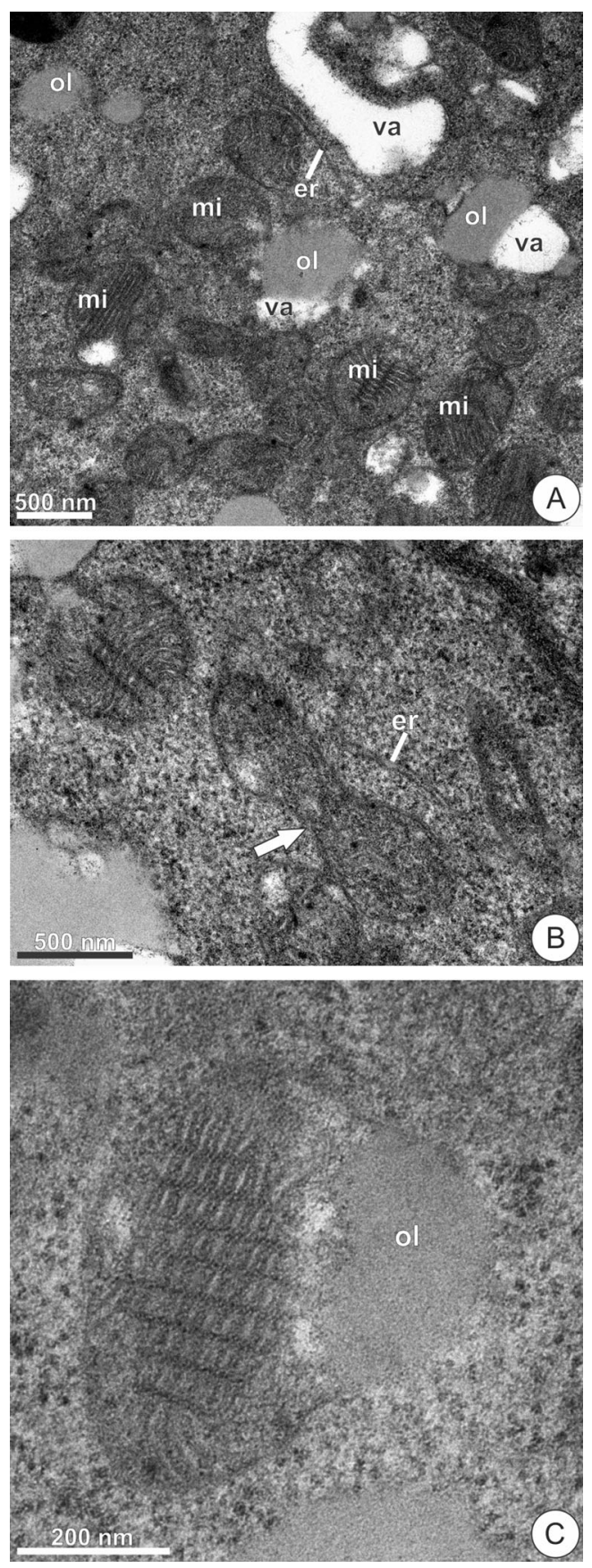

Fig. 6 TEM images of mature secretory cavities in Metrodorea nigra. a Innermost epithelial cell showing dense cytoplasm, abundant mitochondria $(m i)$ with developed cristae, and oil $(o l)$ bodies in vacuoles $(v a)$ and scattered throughout the cytoplasm. b Mitochondria exhibiting convoluted and tubular cristae, electron-dense junctions, and black granules in the matrix. Note the region of constriction (arrow) in the mitochondria, suggesting fission. $\mathbf{c}$ Mitochondria exhibiting a crystalline core and oil $(o l)$ inclusion. er endoplasmic reticulum

tissue analysis to confirm the consistency of our results. The different fixatives and embedding media employed produced similar preservations of secretory cavities for analysis under the light microscope. Good results were obtained with the resin embedding, since the sections allowed us to analyze entire shoot apices as well as intact cavities, with accumulation of secretions in the lumen. The staining of the tissue sections $(4-6 \mu \mathrm{m})$ with toluidine blue showed to be very efficient in characterizing the cells and their cytoplasmic contents. The analysis of slices of fresh material, obtained with the aid of a Ranvier microtome $(8-10 \mu \mathrm{m})$, revealed the chemical nature of the main classes of substances present in the epithelial cells and in the lumen of the secretory cavities. Aldehyde fixation has been reported to cause artefactual swelling and rupture of the epithelial cells in Citrus limon (Turner et al. 1998), and other techniques, such as high pressure freezing followed by freeze substitution, have been employed (Turner and Lange 2015). However, the conventional method of tissue fixation for TEM analysis (employing a combination of aldehyde fixation plus osmium tetroxide post-fixation) allowed us the characterization of the ultrastructural organization of epithelial cells in different developmental stages, as well as the preservation of lipid droplets, in a similar way described in several studies of oil glands in different groups of plants (Knight et al. 2001; Liang et al. 2006; Milani et al. 2012; Rodrigues and Machado 2012; Possobom et al. 2015).

In M. nigra, the continuity of oil secretion throughout shoot system development is ensured by the continuing replacement of the damaged inner epithelial cells by divisions in the parenchyma layer that surrounds the secretory epithelium, like a meristematic sheath. This pattern of gland development is similar to that described for some Leguminosae species and constitutes an open model of gland development (Rodrigues et al. 2011a, 2011b). A similar organization was described in secretory cavities of Citrus deliciosa, but it was interpreted as a protective sheath (Bosabalidis and Tsekos 1982a, b). Features suggesting the occurrence of intrusive growth were observed during the gland development. Apical intrusive growth requires swelling followed by dissolution of the middle lamellae of the adjacent cells to create spaces for the cell tip growth to proceed (Siedlecka et al. 2008). The organelle populations in the tapered ends of these epithelial cells are especially interesting. These include extensive RER, abundance of free ribosomes, multivesicular bodies (spherical endosomal organelles that fuse with the plasma membrane or tonoplast in an exocytotic manner), and paramural bodies (small vesicles situated between the cell wall and the plasma membrane). This organelle population is consistent with the synthesis and transport of enzymes which participate in cell wall degradation and/or synthesis processes (Fahn 1979; Evert 2006). All these are features associated with intrusive growth. Other methods, including immunogold labeling and cytochemical localization of enzymes such as pectinase and cellulase, will be used in future work to confirm the occurrence of intrusive growth of the epithelial cells.

The process of differentiation of epithelial cells in M. nigra includes the accumulation of large oil bodies inside the plastids and vacuoles in the early stages of gland development. 

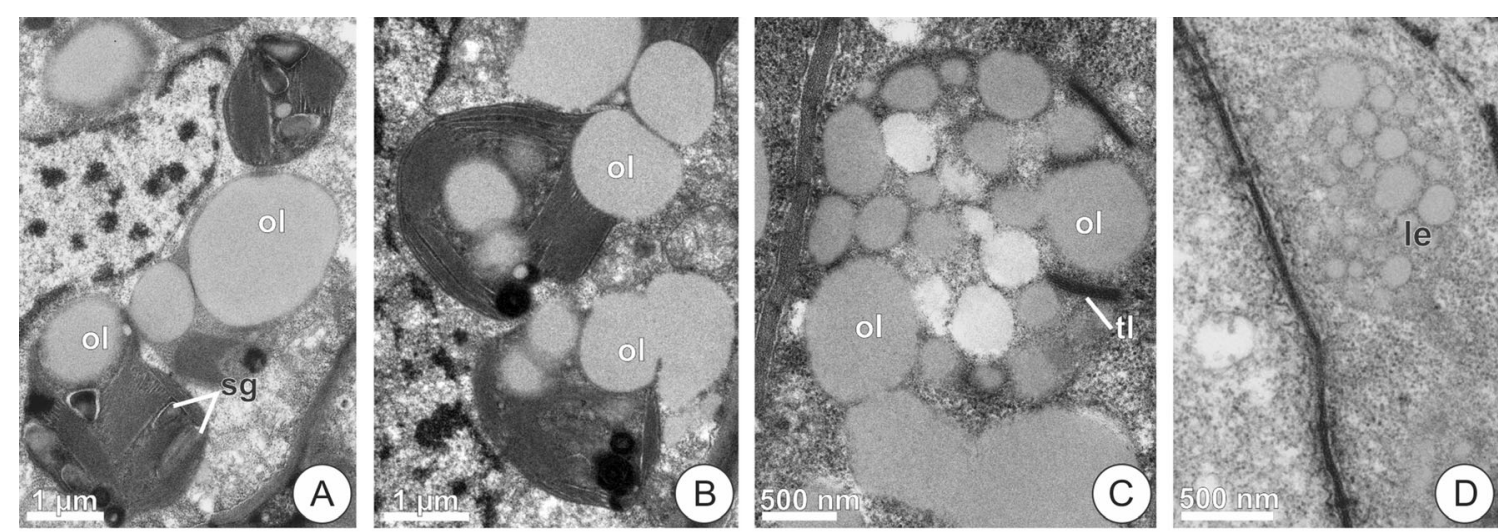
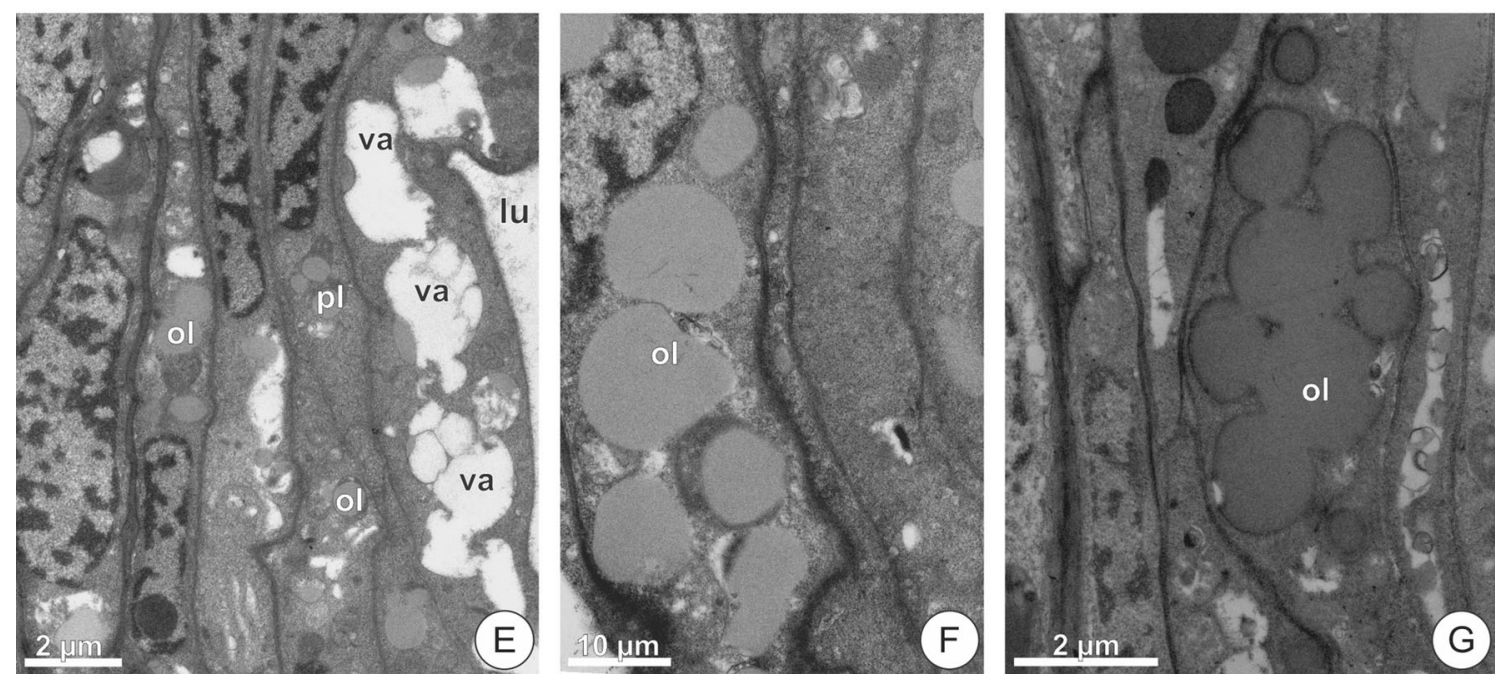

Fig. 7 TEM images of maturing secretory cavities of Metrodorea nigra. a-d Plastid changes. a Plastids with thylakoids, starch grains ( $\mathrm{sg}$ ), and oil $(o l)$ inclusions in the immediate derivative gland cell. b Oil $(o l)$ extrusion of plastids in maturing glands. Note residual starch grains. $\mathbf{c}$ Plastids with thylakoid $(t l)$ remains and filled with abundant oil $(o l)$ bodies in maturing epithelial cell. $\mathbf{d}$ Leucoplast (le) in mature epithelial cell. $\mathbf{e}-\mathbf{g}$ Oil bodies in

This is as commonly described for oil cavities in Citrus (Turner and Lange 2015). However, our ultrastructural analyses show that initial and immediate derivative cells have features that are similar to those of mature epithelial cells. This suggests that the process of oil secretion begins prior to lumen formation. Polyribosomes, numerous vesicles, and rough endoplasmic reticulum are indicative of cytoplasmic synthesis required for cell metabolism and monoterpene biosynthesis (Turner and Croteau 2004). Furthermore, these organelles may be associated with the glycosylation of secretion compounds, particularly some of the toxic components of essential oils (Figueiredo and Pais 1994).

The epithelial cells of mature oil glands of $M$. nigra share a number of common features with other metabolically active cells, such as a high density of ribosomes, a large nucleus-tocytoplasm volume ratio, and relatively small vacuoles (Fahn 1979; Evert 2006). In addition, the presence of endoplasmic reticulum tubular elements, leucoplast, and well-developed mitochondria with osmiophilic granulations has been the gland cells. e Large oil $(o l)$ drops scattered throughout the cytoplasm and inside vacuoles $(v a)$ and plastids $(p l)$ of the epithelial cells. Note an increase in abundance and size of oil drops from the outermost epithelial cells toward the lumen $(l u)$. f Signs of the oil (ol) bodies' coalescence. $\mathbf{g}$ Large oil $(o l)$ body inside vacuole resulting from the oil droplets fusion

described in glands producing terpenes (Turner et al. 1999; Machado et al. 2006; Paiva et al. 2008; Rodrigues et al. 2011a, 2011b; Rodrigues and Machado 2012; Lange and Turner 2013; Turner and Lange 2015; Sá-Haiad et al. 2015; Possobom et al. 2015; Sadala-Castilho et al. 2016). The close spatial relationship of plastids with the endoplasmic reticulum, as observed in the oil cavity of M. nigra, is another feature that is commonly reported for terpene glands (Sá-Haiad et al. 2015 and literature therein). It is believed that the association of these organelles could prevent possible poisoning of the cytoplasm by essential oil during its migration from one compartment to the other (Heinrich 1969; Bosabalidis and Tsekos 1982a, b). The close arrangement of the endoplasmic reticulum cisternae around the plastids has been associated with the facilitation of fatty acid transfer between different sites of glycerolipid biosynthesis (Turner and Lange 2015 and literature cited therein).

Different mechanisms of secretion release have been described to a wide range of secretory structures including oil 
glands (Fahn 1979; Roshchina and Roshchina 1993; Evert 2006). After synthesis, secretory products commonly leave the protoplast and accumulate in the periplasmic space by crossing the plasma membrane by means of transporters (eccrine mechanism) or fusion with membranous vesicles or endoplasmic reticulum profiles (granulocrine mechanism). Then, the secretions cross the cell walls, through the wall capillaries that are formed during the dissolution of the interfibrilar matrix toward the lumen of the secretory cavity (Bosabalidis and Tsekos 1982b). Here, our observations suggest that the mechanism of the movement of lipids to the central cavity does not involve eccrine and (or) granulocrine mechanisms. However, our results showing the extrusion of vacuole content into the lumen, in an exocytotic manner, are particularly interesting. This differs of the usual mechanisms described for secretion release from the epithelial cells, since the bulk of oil bodies accumulated in vacuoles is directly released into the extracellular space. Notably, epithelial cell walls that border the lumen of the secretory cavity undergo a continuous peeling, making it very thin and fragile or almost absent. In this study, the cellular apparatus of the epithelial cells is consistent with production of the enzymes (pectinases and cellulases) involved in the middle lamella and cell wall changes that occur during development of the secretory cavities (Liang et al. 2009). The occurrence of vacuole extrusion in this study will open a new perspective to better understanding of various mechanisms of transport and accumulation of secreted oil in the lumen of secretory cavities.

A striking feature of M. nigra was the gradual differentiation of chloroplasts in large globular leucoplasts during the maturation of the oil secretory cavities. This result is consistent with frequent reports on plastid changes in the oil glands of other representatives of Rutaceae (Bosabalidis and Tsekos 1982a, b). Another striking feature of M. nigra was the varied morphology and topology of mitochondrial cristae along the epithelial layers of oil cavities. Such mitochondrial features have been reported in different organisms and can directly affect the diffusion of metabolites and proteins between internal mitochondrial compartments (Mannella 2006 and literature cited therein). Remodeling (structural transitions) of the mitochondrial inner membrane has been associated with the apoptotic pathway (Epand et al. 2002; Scorrano et al. 2002) and intracellular production of reactive oxygen species (ROS) (Deng et al. 2002). Meanwhile, the electron-dense junctions between mitochondrial cristae, which form symmetrical shapes as observed in this study, can be formed after extreme osmotic swelling and recontraction of the inner membrane (Mannella 2006 and literature cited therein). Major changes in the morphology and topology of the mitochondrial inner membrane were observed in the innermost epithelial cells facing the lumen that will shortly undergo lysis. To date, we do not know if the accumulated oil in the lumen of $M$. nigra affects the osmotic properties of the innermost epithelial cells or has some cytotoxic effect, changing the topology of the endomembrane system. In this sense, we consider secretory cavities to be a suitable biological model with which to study the remodeling of the endomembrane system.

In this study, we demonstrated that oil production begins very early in the young organs of the shoot apex in their dormant stage and continues throughout their expansion stage (shoot system development). Unlike previous microscopic studies that reported a prolonged metabolic activity of the epithelial cells throughout an extended time course of Citrus fruit development (Knight et al. 2001; Yamasaki and Akimitsu 2007; Voo et al. 2012; Turner and Lange 2015), our observations showed that the secretory epithelium has a well defined cycle, with centripetal maturation, of which the damaged innermost epithelial cells facing the lumen are continuously replaced by a meristematic sheath. This pattern ensures the gland functioning throughout shoot system development in M. nigra.

Although the lipids are the most abundant category of chemical compounds in the exudate of the secretory cavities of $M$. nigra, the histochemical analysis indicated the presence of heterogeneous secretion. Presence of lipids, essential oils, and alkaloids reinforces the protective role of the oil glands against herbivores and pathogens (Harborne 1997). The presence of oils in the gland exudates makes the secretion more fluid and may act in the lubrication and protection against dehydration of developing organs (Sá-Haiad et al. 2015). In addition, the products of the generalized dissolution of cell walls likely can contribute to the exudate (see Canaveze and Machado 2015). This observation is of particular importance if we consider that fragments of oligosaccharides originating from cell wall degradation may act in defense against microorganisms (Braga and Dietrich 1987). Considering the gland location, time of performance, and secretion composition, our findings highlight the protective role of the secretory cavities during the dormancy period of the shoot apex and initial shoot expansion. The approach described here will allow expansion of our knowledge on the functioning of oil cavities in the shoot apices of other perennial species that exhibit rhythmic growth.

Acknowledgements The authors thank Sandra Maria CarmelloGuerreiro for assisting in processing of tissues for light microscopy and the technical team of the Electron Microscopy Center of UNESP, Botucatu, for assistance in processing the materials. This work was supported by the Fundação de Amparo à Pesquisa do Estado de São Paulo (FAPESP, Biota Program, 2008/55434-7) and the Conselho Nacional de Desenvolvimento e Pesquisa (CNPq, Universal 470649/2008-9; PQ SRM 02657/2011-8).

\section{Compliance with ethical standards}

Conflicts of interest The authors declare that they have no conflict of interest. 


\section{References}

Bennici A, Tani C (2004) Anatomical and ultrastructural study of the secretory cavity development of Citrus sinensis and Citrus limon: evaluation of schizolysigenous ontogeny. Flora 199:464-475

Bosabalidis A, Tsekos I (1982a) Ultrastructural studies on the secretory cavities of Citrus deliciosa Ten. I Early stages of the gland cells differentiation. Protoplasma 112:55-62

Bosabalidis A, Tsekos I (1982b) Ultrastructural studies on the secretory cavities of Citrus deliciosa Ten. II Development of the essential oilaccumulating central space of the gland and process of active secretion. Protoplasma 112:63-70

Braga MR, Dietrich SMC (1987) Defesas químicas de plantas: fitoalexinas. Acta Bot Bras 1:3-16

Burt S (2004) Essential oils: their antibacterial properties and potential applications in foods - a review. Int J Food Microbiol 94:223-253

Canaveze Y, Machado SR (2015) Leaf colleters in Tabernaemontana catharinensis A.DC. (Apocynaceae, Rauvolfioideae): structure, ontogenesis and cellular secretion. Botany 93:287-296

Carr DJ, Carr SGM (1970) Oil glands ducts in Eucalyptus l'Hérit. II. Development and structure of oil glands in the embryo. Aust J Bot $18: 191-212$

Chen Y, Wu H (2010) Programmed cell death involved in the schizolysigenous formation of the secretory cavity in Citrus sinensis L. (Osbeck). Chin Sci Bull 55:2160-2168

Cruz R, Duarte M, Pirani JR, Melo-de-Pinna GFA (2015) Development of leaves and shoot apex protection in Metrodorea and related species (Rutaceae). Bot J Linn Soc 178:267-282

Cunha AR, Martins D (2009) Classificação climática para os municípios de Botucatu e São Manuel-SP. Irriga 14:1-11

David R, Carde JP (1964) Coloration differentielle dês inclusions lipidique et terpeniques des pseudophylles du pine maritime au moyen du reactif Nadi. C R Acad Sci Paris, Série D 257:1338-1340

Deng Y, Kohlwein S, Mannella CA (2002) Fasting induces cyanideresistant respiration and oxidative stress in the amoeba Chaos carolinensis: implications for the cubic structural transition in mitochondrial membranes. Protoplasma 219:160-167

Epand RF, Martinou J-C, Fornallaz-Mulhauser M, Hughes DW, Epand RM (2002) The apoptotic protein tBid promotes leakage by altering membrane curvature. J Biol Chem 277:32632-32639

Esau K (1965) Plant anatomy. Wiley, New York

Evert RF (2006) Esau's plant anatomy, meristems, cells, and tissues of the plant body - their structure, function, and development. Wiley, New Jersey

Fahn A (1979) Secretory tissues in plants. Academic Press, London

Feder N, O'Brien TP (1968) Plant microtechnique: some principles and new methods. Am J Bot 55:123-142

Figueiredo AC, Pais MS (1994) Ultrastructural aspects of glandular cells from the secretory trichomes from the cell suspension cultures of Achillea millefolium L. ssp. millefolium. Ann Bot 74:179-190

Guidugli MC, Ferreira-Ramos R, de Sousa ACB, Cidade FW, Marconi TG, Mestriner MA, Groppo M, Alzate-Marin AL (2012) Genetic diversity of Metrodorea nigra (Rutaceae) from a small forest remnant in Brazil assessed with microsatellite markers. Genet Mol Res $11: 10-16$

Haberlandt G (1914) Physiological plant anatomy. Macmillan, London

Harborne JB (1997) Biochemical plant ecology. In: Dey PM, Harborne JB (eds) Plant biochemistry. Academic Press, London, pp. 503-516

Hayat MA (1989) Principles and techniques of electron microscopy: biological applications. CRC Press, Boca Raton

Heinrich G (1966) Licht-und elektronenmikroskopische Untersuchungen zur Genese der Exkrete in den lysigenen Exkreträumen von Citrus medica. Flora 156A:451-456
Heinrich G (1969) Elektronenmikroskopische Beobachtungen zur Entstehungsweise der Exkretbehälter von Ruta graveolens, Citrus limon und Poncirus trifoliata. Oesterr Bot Z 117:397-403

Jensen WA (1962) Botanical histochemistry: principles and practice. W. H. Freeman and Company, San Francisco

Jin XL, Du YQ (2002) Advance in study on cultivation and management of bergamot. Spec Wild Eco Animal Plant Res 2:48-55

Johansen DA (1940) Plant microtechnique. McGraw-Hill, New York

Judd WS, Campbell CS, Kellogg EA, Stevens PF, Donoghue MJ (2008) Plant systematics: a phylogenetic approach. Sinauer Associates Inc., Sunderland, Mass

Kalemba D, Kunicka A (2003) Antibacterial and antifungal properties of essential oils. Curr Med Chem 10:813-829

Knight TG, Klieber A, Sedgley M (2001) The relationship between oil gland and fruit development in Washington navel orange (Citrus sinensis L. Osbeck). Ann Bot 88:1039-1047

Lange BM, Turner GW (2013) Terpenoid biosynthesis in glandular trichomes-current status and future opportunities. Plant Biotechnol J 11:2-22

Liang SJ, Wu H, Lun X, Lu DW (2006) Secretory cavity development and its relationship with the accumulation of essential oil in fruits of Citrus medica L. var. sarcodactylis (Noot.) Swingle. J Integr Plant Biol 48:573-583

Liang S, Wang H, Yang M, Wu H (2009) Sequential actions of pectinases and cellulases during secretory cavity formation in Citrus fruits. Trees 23:19-27

Liu P, Liang S, Yao N, Wu H (2012) Programmed cell death of secretory cavity cells in fruits of Citrus grandis cv. Tomentosa is associated with activation of caspase 3-like protease. Trees Struct Funct 26: $1821-1835$

Machado SR, Guimarães EM, Gregório EA (2006) Ovary peltate secretory trichomes of Zeyheria montana (Bignoniaceae): developmental ultrastructure and secretion in relation to function. Ann Bot 97:357369

Mandalari G, Bennett RN, Bisignano G et al (2007) Antimicrobial activity of flavonoids extracted from bergamot (Citrus bergamia Risso) peel, a byproduct of the essential oil industry. J Appl Microbiol 103: 2056-2064

Mannella CA (2006) Structure and dynamics of the mitochondrial inner membrane cristae. Biochim Biophys Acta 1763:542-548

Mazia D, Brewer PA, Alfert M (1953) The cytochemical staining and measurement of protein with mercuric bromophenol blue. Biol Bull 104:57-67

Milani JF, Rocha JF, Teixeira SP (2012) Oleoresin glands in copaiba (Copaifera trapezifolia Hayne: Leguminosae), a Brazilian rainforest tree. Trees 26:769-775

Moraes Filho RM, Bonifácio-Anacleto F, Alzate-Marin AL (2015) Fragmentation effects and genetic diversity of the key semidecidual forest species Metrodorea nigra in Southwestern Brazil. Genet Mol Res 14:3509-3524

O'Brien TP, Feder N, McCully ME (1964) Polychromatic staining of plant cell walls by toluidine blue. Protoplasma 59:368-373

Oliva A, Di Blasio B, Cafiero G, Aliotta G, Iacovino R, DeFeo V (2000) Allelochemicals from rue (Ruta graveolens L.) and olive (Olea europaea L.) oil mill waste waters as potential natural pesticides. Curr Top Phytochem 3:167-177

Paiva EAS, Oliveira DMT, Machado SR (2008) Anatomy and ontogeny of the pericarp of Pterodon emarginatus Vogel (Fabaceae Faboideae) with emphasis on secretory ducts. A Acad Bras Ciênc $80: 455-465$

Pombal ECP, Morellato LPC (2000) Differentiation of floral color and odor in two fly pollinated species of Metrodorea (Rutaceae) from Brazil. Plant Syst Evol 221:141-156

Possobom CCF, Guimarães E, Machado SR (2015) Structure and secretion mechanisms of floral glands in Diplopterys pubipetala (Malpighiaceae), a neotropical species. Flora 211:26-39 
Regnault-Roger C (1997) The potential of botanical essential oils for insect. Integr Pest Manag Rev 2:25-34

Reynolds ES (1963) The use of lead citrate at high $\mathrm{pH}$ as an electron-opaque stain in electron microscopy. J Cell Biol 17:208

Rodrigues TM, Machado SR (2012) Oil glands in Pterodon pubescens Benth.(Leguminosae-Papilionoideae): distribution, structure, and secretion mechanisms. Int J Plant Sci 173:984-992

Rodrigues TM, Teixeira SP, Machado SR (2011a) The oleoresin secretory system in seedlings and adult plants of copaíba (Copaifera langsdorffii Desf., Leguminosae-Caesalpinioideae). Flora 206: 585-594

Rodrigues TM, Santos DC, Machado SR (2011b) The role of the parenchyma sheath and PCD during the development of oil cavities in Pterodon pubescens (Leguminosae-Papilionoideae). C R Biol 334: 535-543

Roshchina VV, Roshchina VD (1993) The excretory function of higher plants. Springer, Berlin

Sadala-Castilho R, Machado SR, Sá-Haiad B, Lima HA (2016) Oil-resin glands in Velloziaceae flowers: structure, ontogenesis and secretion. Plant Syst Evol 302:585-599

Sá-Haiad B, Silva CP, Paula RCV, Rocha JF, Machado SR (2015) Androecia in two Clusia species: development, structure and resin secretion. Plant Biol 17:816-882

Scorrano L, Ashiya M, Buttle K, Weiler S, Oakes SA, Mannella CA, Korsmeyer SJ (2002) A distinct pathway remodels mitochondrial cristae and mobilizes cytochrome c during apoptosis. Dev Cell 2:55-67
Siedlecka A, Wiklund S, Péronne M-A et al (2008) Pectin methyl esterase inhibits intrusive and symplastic cell growth in developing wood cells of Populus. Plant Physiol 146:554-565

Thomson WW, Platt-Aloia K, Endress AG (1976) Ultrastructure of oil gland development in the leaf of Citrus sinensis L. Bot Gaz 137: 330-340

Turner GW, Croteau G (2004) Organization of monoterpene biosynthesis in Mentha. Immunocytochemical localization of geranyl diphosphate synthase limonene-6-hydroxylase, isopiperitenol dehydrogenase, and pulegone reductase. Plant Physiol 136:4215-4227

Turner GW, Lange BM (2015) Ultrastructure of grapefruit secretory cavities and immunocytochemical localization of (1)-limonene synthase. Int J Plant Sci 176:643-661

Turner GW, Lange BM, Gifford EM (1998) Schizogenous secretory cavities of Citrus union (L.) Burm. F. and a re-evaluation of the lysigenous gland concept. Int J Plant Sci 159:75-88

Turner GW, Gershenzon J, Nielson EE, Froehlich JE, Croteau RB (1999) Limonene synthase, the enzyme responsible for monoterpene biosynthesis in peppermint, is localised of oil gland secretory cells. Plant Physiol 120:879-886

Voo SS, Grimes HD, Lange BM (2012) Assessing the biosynthetic capabilities of secretory glands in Citrus peel. Plant Physiol 159:81-94

Yamasaki Y, Akimitsu K (2007) In situ localization of gene transcriptions for monoterpene synthesis in irregular parenchymic cells surrounding the secretory cavities in rough lemon (Citrus jambhiri). J Plant Physiol 164:1436-1448 